\title{
Keratin 5 knockout mice reveal plasticity of keratin expression in the corneal epithelium
}

\author{
Hong Lu ${ }^{\mathrm{a}, 1}$, Alexander Zimek ${ }^{\mathrm{b}, 1}$, Jian Chen ${ }^{\mathrm{a}}$, Michael Hesse ${ }^{\mathrm{a}, 2}$, Heinrich Büssow ${ }^{\mathrm{c}}$, \\ Klaus Weber ${ }^{\mathrm{b}}$, Thomas M. Magin ${ }^{\mathrm{a}, *}$ \\ anstitut für Physiologische Chemie, Abteilung für Zellbiochemie, Bonner Forum Biomedizin and LIMES, \\ Rheinische Friedrich-Wilhelms-Universität, Nussallee 11, D-53115 Bonn, Germany \\ ${ }^{\mathrm{b}}$ Max Planck Institute for Biophysical Chemistry, Goettingen, Germany \\ ${ }^{\mathrm{c}}$ Anatomisches Institut, Rheinische Friedrich-Wilhelms-Universität, Bonn, Germany
}

Received 20 January 2006; received in revised form 3 April 2006; accepted 7 April 2006

\begin{abstract}
We have recently demonstrated that the keratin $\mathrm{K} 3$ gene, which is active in the suprabasal human corneal epithelium, is missing in the genome of the mouse. We show that a normal $\mathrm{K} 3$ gene exists in a wide variety of mammals while in rodents the gene is converted to a pseudogene with a very strong sequence drift. The availability of $\mathrm{K} 5^{-1-}$ mice provides a unique opportunity to investigate type-specific keratin function during corneal differentiation in the absence of both K5 and K3. Here, we report that the deletion of K5, which in wild-type mice forms a cytoskeleton with K12, does neither cause keratin aggregation nor cytolysis in the cornea. This is due to the induction of K4 in corneal epithelial cells, normally restricted to corneal stem stem cells residing in the limbus. Using a combination of antibodies and RT-PCR, we identified additional keratins expressed in the mouse cornea including K23 which was previously thought to be specific for pancreatic carcinomas. This reflects an unexpected complexity of keratin expression in the cornea. Our data suggest that in the absence of mechanical stress, corneal differentiation does not depend on distinct keratin pairs, supporting a concept of functional redundancy, at least for certain keratins.
\end{abstract}

(C) 2006 Elsevier GmbH. All rights reserved.

Keywords: Intermediate filaments; Keratins; Cornea; Epidermolysis bullosa simplex; Regeneration

\footnotetext{
*Corresponding author. Tel.: + 49228734444 ; fax: +49228734558 .

E-mail address: t.magin@uni-bonn.de (T.M. Magin).

URL: http://www.zellbiochemie.uni-bonn.de.

${ }^{1}$ These two authors contributed equally.

${ }^{2}$ Present address. Faculty of Medicine, Department of Biochemistry and Molecular Biology, University of Calgary, 3330 Hospital Drive, N.W. Calgary, Alta., Canada T2N 4N1.
}

\section{Introduction}

The two major properties of the corneal epithelium needed for normal vision are first to form a smooth refractive surface through its interaction with the tear film and second to form a protective tight junctional barrier that prevents decreases in net fluid transport out from the stroma and prevents corneal penetration by pathogens. During embryogenesis, the corneal epithelium is initially continuous with the surface ectoderm, but during later developmental stages appears to arise 
from the superficial cells of the corneal stroma. The corneal epithelium varies in thickness depending on the status of the eyelids, either fused or open. As long as the eyelids are fused, the epithelium is only one to two layers of cells present in the central cornea, the limbus and the conjunctiva. When the eyelids are open, four to five cell layers cover the central cornea. The corneal epithelium continues to increase until it reaches its adult level of six to seven cell layers (Sevel and Isaacs, 1988; Zieske, 2004). The main difference between human and mouse corneal epithelium development is that the human eyelids open around 24 weeks of gestation, while the mouse eyelids open two weeks after birth. In adult mice, the stem cells from limbal basal epithelial cells differentiate and migrate centrally to form the basal cell layer of the corneal epithelium. The more differentiated and more proliferating keratinocytes of the basal layer are able to undergo few cell divisions prior to their upward migration which results in their final differentiation which serves to replace the loss of differentiated superficial cells ( $\mathrm{Lu}$ et al., 2001; Wolosin et al., 2004).

Keratins form the intermediate filament (IF) cytoskeleton in epithelia including cornea. They are encoded by a large multigene family of 54 individual members in humans and the mouse, and are classified into two major sequence types, type I and type II. Type I keratins include K9-K23, and the hair keratins Ha1-Ha8. Type II keratins include $\mathrm{K} 1-\mathrm{K} 8$, and the hair keratins, Hb1-Hb6. All type I keratin genes, except for K18, are clustered on human chromosome $17 \mathrm{q} 21$ in synteny to mouse chromosome $11 \mathrm{D}$, whereas the type II cluster, localized on human chromosome $12 \mathrm{q} 13$ is synteneous to mouse chromosome 15F (Hesse et al., 2004). In vivo, at least one member of each family is necessary to form obligate heterodimeric double-stranded coiled coils. The expression of particular pairs of type I and type II keratins is tissue specific, differentiation dependent, and developmentally regulated (Galvin et al., 1989; Lu et al., 2005; O'Guin et al., 1987; Quinlan et al., 1985). The keratin pair $\mathrm{K} 5 / \mathrm{K} 14$, for example, is found in the basal cell layer of all stratified epithelia (Lloyd et al., 1995; Peters et al., 2001; Tong and Coulombe, 2004), whereas the $\mathrm{K} 1 / \mathrm{K} 10$ keratin pair is expressed by suprabasal and superficial epidermal epithelial cells (Herzog et al., 1994; Swensson et al., 1998).

The ocular surface epithelial lineages share many of the basic features of the epidermal system, including the expression of tissue-specific keratin pairs. In the human adult ocular surface epithelia, the switch is from $\mathrm{K} 5 / \mathrm{K} 14$ to K3/K12 pairs, which are characteristic of cornea-type epithelial (Schermer et al., 1986; Sun et al., 1983); K4 is typical of conjunctival epithelia (Kurpakus et al., 1994). In the mouse, the keratin expression pattern is slightly different. Murine K12 is also corneal epithelial cell specific (Liu et al., 1993, 1994), while the murine K4 is expressed in conjunctival and in stratified, non-cornified epithelia (Kurpakus et al., 1994; Quinlan et al., 1985). Remarkably, the monoclonal antibody AE5 which is specific to K3 of many mammalian species including rabbit, cow, dog and human does not stain mouse corneal epithelia (Chaloin-Dufau et al., 1993). Recently, an in silico study showed that the gene for human cornea K3 located between genes K9 and K4 lacks a murine counterpart (Hesse et al., 2004). Until now it is not clear which type II keratin expressed in the mouse corneal epithelia forms a keratin pair with K12. Keratin $\mathrm{K} 5$ might be the most likely candidate (Hesse et al., 2004).

During the development of the mouse cornea, K12 is first detected in corneal epithelial cells of E15 in a small subpopulation of superficial cells. At later developmental stages, only suprabasal corneal epithelium expressed $\mathrm{K} 12$, however, in postnatal and adult cornea all cell layers are K12-positive. K4 was first observed, in E14 and E15 embryos, in a subpopulation of epithelial cells which had invaginated from surface ectoderm to form the lid buds. From embryonic day 16 onwards, K4 was detected in all areas of developing conjunctival epithelium (Kurpakus et al., 1994; Zhang et al., 2005).

Mutations in human K14/K5 genes (Coulombe et al., 1991; Lane et al., 1992; Magin et al., 2004) have been linked to human skin diseases, including epidermolysis bullosa simplex (EBS). Similar clinical manifestation of these diseases have first been reproduced in transgenic mice carrying dominant negative mutations of these keratin genes (Vassar et al., 1991). We have previously generated $\mathrm{K} 5^{-1-}$ mice as a model for EBS (Peters et al., 2001). In these mice, the fragile epidermis was no longer attached to the dermis due to the absence of keratin filaments, resulting in perinatal death. These results demonstrated that keratin intermediate filaments are vital for the integrity of the basal epidermis.

In the present study, we investigated the keratin expression pattern in adult mouse cornea. We took advantage of the $\mathrm{K}^{-1-}$ mouse model to clarify which type II keratin form pairs with K12 when neither K 3 nor K5 are present in mouse corneal epithelium. Furthermore, we argue that the human $\mathrm{K} 3$ gene is not the result of a recent gene duplication followed by sequence drift but documents an older mammalian gene, which was specifically lost on the rodent lineage.

\section{Materials and methods}

\section{Animal experiments}

$\mathrm{K} 5^{-/-}$neonatal mice were generated as described (Peters et al., 2001). Eyeballs with corneae from wildtype and $\mathrm{K}^{-1-}$ neonatal mice as well as wild-type adult mice, guinea pig, rat and rabbit were surgically removed 
after the animals had been killed by $\mathrm{CO}_{2}$. Fresh eyeballs were embedded in Tissue-Tek for immunofluorescence, or stored in RNAlater for subsequent microdissection of corneal tissue for RT-PCR as described below in detail, or corneas were excised and cut into small pieces for electron microscopy. Genotyping of the wild-type, heterozygous and $\mathrm{K}^{-1-}$ mice was performed with tail DNA by PCR as described previously (Lu et al., 2005).

All animal experiments were carried out according to the Animal Care Guidelines of both University of Bonn and Max Planck Institute for Biophysical Chemistry with permission of the local administration.

\section{Transmission electron microscopy}

Fixation and processing of tissue specimens for electron microscopy was carried out as described before (Reichelt et al., 2001).

\section{Murine cornea library}

Twenty eyes were dissected from adult NMRI mice and stored in RNAlater (Qiagen, Hilden, Germany) for $1 \mathrm{~h}$ to prevent RNA degradation. Eyes were fixed on sylgaard dishes with insect needles and cornea tissue was cut with a trepan, a hollow surgical instrument (diameter $1 \mathrm{~mm}$ ) and stored in RNAlater. Tissue was crushed in a mortar and subsequently homogenized with a rotor homogenizer following the Qiagen RNeasy protocol. Total RNA was eluted in $50 \mu 1 \mathrm{H}_{2} \mathrm{O}$. Thirty $\mu \mathrm{l}$ were used for preparation of a cDNA library with a ZAP Express cDNA synthesis kit (Stratagene, Heidelberg, Germany) according to the manufacturer's protocol. Size fractionation was performed with a QiaQuick PCR-purification column instead of a drip column.

\section{PCR analysis of the cornea library}

PCR was done with ExTaq polymerase (TaKaRa, Gennevilliers, France) using the amplified library as template. Phages were denatured for $4 \mathrm{~min}$ at $95^{\circ} \mathrm{C}$ prior to PCR to ensure total DNA release. Primer concentrations were set to $30 \mathrm{pMol}$. All PCR products were cloned (TOPO-TA, Invitrogen, Leek, The Netherlands) and sequenced on an ABI-377 DNA sequencer. Results were checked against known murine sequences and the complete mouse genome at <http://genome.ucsc.edu/ cgi-bin/hgBlat $\rangle$, release February 2003 (Karolchik et al., 2003). PCR results with sequence-specific primers for filensin showed that the original cornea tissue was contaminated by lens tissue. Keratin 4 , which is present in conjunctiva, but absent from the cornea (Kurpakus et al., 1994), was not detected. Presence or absence of 28 different keratins was studied by PCR (Table 1). All primers were checked for amplification on cDNAs from various murine tissues with subsequent sequence analysis.

\section{Identification of mammalian $\mathrm{K} 3$ genes}

The automated alignment of human (July 2003), mouse (February 2003) and rat (June 2003) genomes in the genome browser (Chiaromonte et al., 2002; Schwartz et al., 2003) was taken as the starting point for a detailed analysis of the putative homology between the three genomes (Hesse et al., 2004). Human Kb3 exons were aligned to the corresponding regions in the rodent genomes. Additionally, we analyzed the published genomes of dog (July 2004 WGS assembly 1.0), chimpanzee (November 2003 NCBI Build 1.1) and cow (March 2005 assembly Btau_2.0), accessible through the UCSC Genome Browser (genome.ucsc.edu/ cgi-bin/hgBlat).

\section{Antibodies}

The following primary antibodies were used: AF 138 against K5 (1:600, Hiss Diagnostics), $\alpha$-CK14.2 against K14 (1:700, kindly provided by L. Langbein, Heidelberg), Ks 8.07 and Ks 18.04 against K8 and K18, respectively (1:20, Progen, Heidelberg, Germany), Troma 1 against K18 (1:20), TROMA-3 against K19, 693-1 against K6 (kindly provided by M. Blessing; Leipzig); antiK7 against $\mathrm{K} 7$ (kindly provided by Irwin McClean, Dundee), Ks20.10 against K20 (undiluted, kind gift of Prof. Roland Moll, Marburg), pKa23 against K23 (1:2000; Magin lab), 6B10 against K4 (1:10, Progen). Secondary antibodies used for immunofluorescence studies in recommended dilutions were Alexa 488A- or Alexa 594-conjugated goat anti-rabbit, goat anti-mouse, goat anti-rat and goat anti-guinea pig IgG (Molecular Probes, Leiden, The Netherlands) and TexasRedconjugated goat anti mouse IgG1 (Southern Biotechnology).

\section{Immunofluorescence microscopy on corneal tissues}

Isolated eyes were mounted in Tissue-Tek (Sakura Finetek, NL) and frozen in isopentane at $-130{ }^{\circ} \mathrm{C}$. A Leica CM1900 cryomicrotome was used to cut sections of $5 \mu \mathrm{m}$ at $-19^{\circ} \mathrm{C}$. Tissue sections were dried $10-15 \mathrm{~min}$ at room temperature prior to 10 min fixation in acetone $\left(-20^{\circ} \mathrm{C}\right)$. The first antibody was applied to the sections and incubated for 1 hour. After washing 3 times with Tris-buffered saline for $5 \mathrm{~min}$, the secondary antibody was applied and incubated for $30 \mathrm{~min}$, followed by washing for $5 \mathrm{~min} 3$ times. Sections were covered with Mowiol (Sigma). Image analysis and processing were performed using AxionVision 4.2 (Carl Zeiss) and Adobe Photoshop 6.0 software. 
Table 1. Identification of keratin expression in wild-type adult cornea using RT-PCR

\begin{tabular}{|c|c|c|c|c|}
\hline Keratins & Cornea & Forward primer & Reverse primer & {$[\mathrm{bp}]$} \\
\hline \multicolumn{5}{|c|}{ Type-I keratins } \\
\hline K9 & - & CTCGTGGACATCGACAATACTCG & GCTCCAGACGATTCGTCTTGC & 700 \\
\hline K10 & - & GACAATGCCAACGTGCTGCTGC & GATGTCTAGGAGTTGTTGGTACTCG & 660 \\
\hline K12 & + & GCGAAGGGTGCTGGACGAGC & CATCTCCAGGCGAGCCTTGACG & 555 \\
\hline K13 & - & CGAAGAGGAGATGAAGGAATTACGC & GTAGCGGCACTCTGTCTCTGC & 280 \\
\hline K14 & + & CCTGGAGATGCAGATTGAGAGC & CACATCTCTGGATGACTGAGAGC & 770 \\
\hline K15 & + & GACCTGGAGATGCAGATTGAGCAGC & CATCTTAGCATCCTGGTCCTCGAGC & 560 \\
\hline K16 & - & CAATGTGGAGATGGACGCAGC & GCTGAAGCTGGTTGAACCTTGC & 560 \\
\hline K17 & - & CCTGGGTGGAGGTTCATCTCG & GAGACAGCTGCACGCAGTAGC & 1000 \\
\hline K18 & - & CAGCGCAGCCAGCGTCTATGC & CTTGCGGAGTCCATGGATGTCGC & 430 \\
\hline K19 & + & GAACACGCCTTGCGTCTGAGC & CTGGACTTGATGTCCATGAGCTGC & 620 \\
\hline K20 & - & GCATGAGTGGCTCGCTGTATAGG & CAGCTCCGTGACTTGAACCTCG & 800 \\
\hline $\mathrm{Ka} 22^{\mathrm{a}}$ & - & GACGTCAATGTGGAGATGGACG & GCACCTGGTACTCATGATTCTGC & 380 \\
\hline K23 & + & CTTGCCGAGTGACTTCAAGGTCAG & GCACCTTGTGTTCATTGTTCTGACG & 390 \\
\hline $\mathrm{K} 10 \mathrm{~B}^{\mathrm{a}}$ & - & GAACTCTGCCTTCGAGAGTGC & CAGCAGGCATTCGTACTCAGC & 520 \\
\hline \multicolumn{5}{|c|}{ Type-II keratins } \\
\hline $\mathrm{K} 1$ & - & CGAAGAGCTGCAGATCACTGC & CATCAGCTCCTGGAAGTCACG & 280 \\
\hline $\mathrm{K} 2 \mathrm{e}$ & - & CTGCAGCAGTTGGATGTAGGCAGC & CAGAGCTTCTGCCTCCAGAGC & 1000 \\
\hline K4 & - & CTCAGCCATGATCGCCAGACAG & GGACCTCTTGGTGATGGTGGC & 1560 \\
\hline K5 & + & AGTCAACATCTCCGTCGTCAC & GGGACTGCCTAAAAGAAGCAG & 370 \\
\hline K6a & + & CAAAACCACCATCAARAGTCAAAC & CAAAACCACCATCAARAGTCAAAC & 1650 \\
\hline K7 & - & GTTGCTGAAGAAGGATGTGGATGC & CCACTGAAGCTCAGAGCATTGC & 730 \\
\hline K8 & - & GTATGAGGATGAGATCAACAAGC & CGTATGAATGCTCATGTTCTGC & 750 \\
\hline $\mathrm{K} 2 \mathrm{p}$ & - & GCTGAAGAGCATGCAAGACCTG & TGCCTCCACTGCCAAGTCTGC & 910 \\
\hline $\mathrm{K} 6 \mathrm{~b}$ & + & CAAAACCACCATCAARAGTCAAAC & GCTCTGGTAGTTGGGATTTCAG & 1600 \\
\hline K6hf & - & GCAGCTGGATGGCATCACAGC & CCACTGGTCGTGAAGGAGTAGC & 900 \\
\hline $\mathrm{Kb} 20^{\mathrm{a}}$ & + & CACCAАСТССАAАТСТСССТАGC & GCTGTCTTACTCTGAGGCCTC & 1400 \\
\hline K61 & - & CTGGATATGGAGCTGAGGAACG & GCTCACAAGATCCTGGTATTCACG & 630 \\
\hline $\mathrm{K} 1 \mathrm{~b}$ & - & CTGGAGCAGCAGAACCAGGTGC & CCGTGCATCCCTTCGACCTGC & 650 \\
\hline $\mathrm{K} 5 \mathrm{~b}$ & + & CTCCAGGAGATGCAGAGGAAGC & GCATGACCACTTGGCCTGTACC & 1250 \\
\hline \multicolumn{5}{|l|}{ Others } \\
\hline Filensin & + & ССТАTGACTGCAGGCAGCTAGC & CTCTACGTGGCCGTCATGATGC & 700 \\
\hline
\end{tabular}

${ }^{\text {a }}$ Referring to nomenclature by Hesse et al. (2004).

\section{Results and discussion}

\section{Analysis of keratin expression in the murine cornea by RT-PCR}

Corneal tissue was obtained by a surgical instrument, which excluded contamination by conjunctival epithelium. The material was however contaminated by lens tissue. A cDNA library prepared from the cornea material was analyzed for the expression of 28 different keratins using PCR amplification with the primers listed in Table 1. Products were characterized by electrophoresis, cloned, sequenced and compared with the murine genome (Waterston et al., 2002). Keratins are listed in the new general keratin nomenclature (Hesse et al., 2004). All primers used were found to yield the correct keratin cDNA in murine tissues known to express the particular keratin or to amplify gene fragments on genomic DNA as the template. In line with the isolation of cornea material free of conjunctival epithelium we could not detect $\mathrm{K} 4$ which is present in the adult conjunctival epithelium but not in the normal cornea (Kurpakus et al., 1994). Amplification of the cDNA for filensin, a known non-keratin intermediate filament protein restricted to the lens, directly proved the expected contamination. Since the eye lens lacks keratin expression (Perng et al., 2004), this contamination does not influence our analysis of corneal keratins.

Type I keratins positively identified in the cornea by PCR (Table 1) are K12, K14, K15, K19 and K23. Type II keratins of the cornea are K5, K6a, K6b, Kb20 as well as $\mathrm{Kb} 40$. The latter two keratins were only recently identified by analysis of the human and murine keratin gene II cluster available in the complete genomes (Hesse et al., 2004). 


\section{Ultrastructural analysis of the $\mathrm{K5}^{-1-}$ murine cornea}

Our previous study on $\mathrm{K} 5^{-1-}$ mice showed extremely fragile epidermis which lost contact with the dermis. All $\mathrm{K} 5^{-1-}$ mice die within one hour after birth. Histochemistry and transmission electron microscopy showed cytolysis in the basal layer of the epidermis (Peters et al., 2001). Here, electron microscopy was used to check the ultrastructure of the neonatal $\mathrm{K}^{-/-}$and wildtype cornea. At the ultrastructural level, we found no difference between both genotypes of mice (Fig. 1). The histological examination was also made with $\mathrm{K}^{-1-}$ mice cornea and wild-type control. There were no pathological alterations in $\mathrm{K}^{-/-}$cornea (data not shown), most likely, because at birth, the cornea is not fully mature. This was evident from the appearance of small desmosomes and the low abundance of keratin IF in all strata. The few keratin IF detectable by electron microscopy were short and attached to desmosomes and hemidesmosomes.

\section{Keratin expression in the murine cornea by immunofluoresence analysis}

Immunofluorescence was then performed to identify expression of different keratins in neonatal $\mathrm{K}^{-1-}$ and wild-type cornea (Fig. 2A, B). Most notably, K4 was induced in the cornea of $\mathrm{K}^{-/-}$, but not in wild-type cornea (Fig. 2C, D). This suggests that K4 forms IF with K14 in basal and K12 in suprabasal keratinocytes. We could not detect $\mathrm{Kb} 20$ and $\mathrm{K} 23$, either in wild-type or in $\mathrm{K} 5^{-1-}$ corneas by immunofluorescence, while the expression of these two genes could be found in wildtype cornea with RT-PCR as described above. Given that these antisera detect the corresponding keratins in other tissues (Magin et al., unpublished), this might reflect a very low level of expression in neonatal cornea or in a subset of corneal epithelial cells. All together, 10 keratins were examined. The results of the immunofluorescence analysis are listed in Table 2.

Since there is no K3 expressed in the cornea of mice, according to our in silico and immunofluorescence results, $\mathrm{K} 5$ is the most probable candidate to form IF with K12 in the cornea of neonatal mice. Remarkably, K4 was not only expressed in the conjunctiva, but also in the cornea of $\mathrm{K}^{-1-}$ mice to replace $\mathrm{K} 5$. In its presence, no cytolysis or structural changes were noted in the $\mathrm{K}^{-1-}$ compared to the wild-type cornea, suggesting that the K4/K14 pair was functional. This is supported by several in vitro and in vivo data. Although the in vitro assembly of some unnatural type I and type II keratin pairs has revealed subtly altered properties, they can still form polymers (Yamada et al., 2002). Furthermore, K5/K16 polymers partially rescued the skin blistering of K14 null mice (Paladini and Coulombe, 1999). During the embryonic development of $\mathrm{K} 5^{-1-}$ mice, $\mathrm{K} 8$ forms IF together with $\mathrm{K} 14$ from E9.5 until E13.5, when K8 is still expressed in the singlelayered surface ectoderm ( $\mathrm{Lu}$ et al., 2005).

The development of the cornea is different in mouse and humans. Neonatal mice have only one to two layers
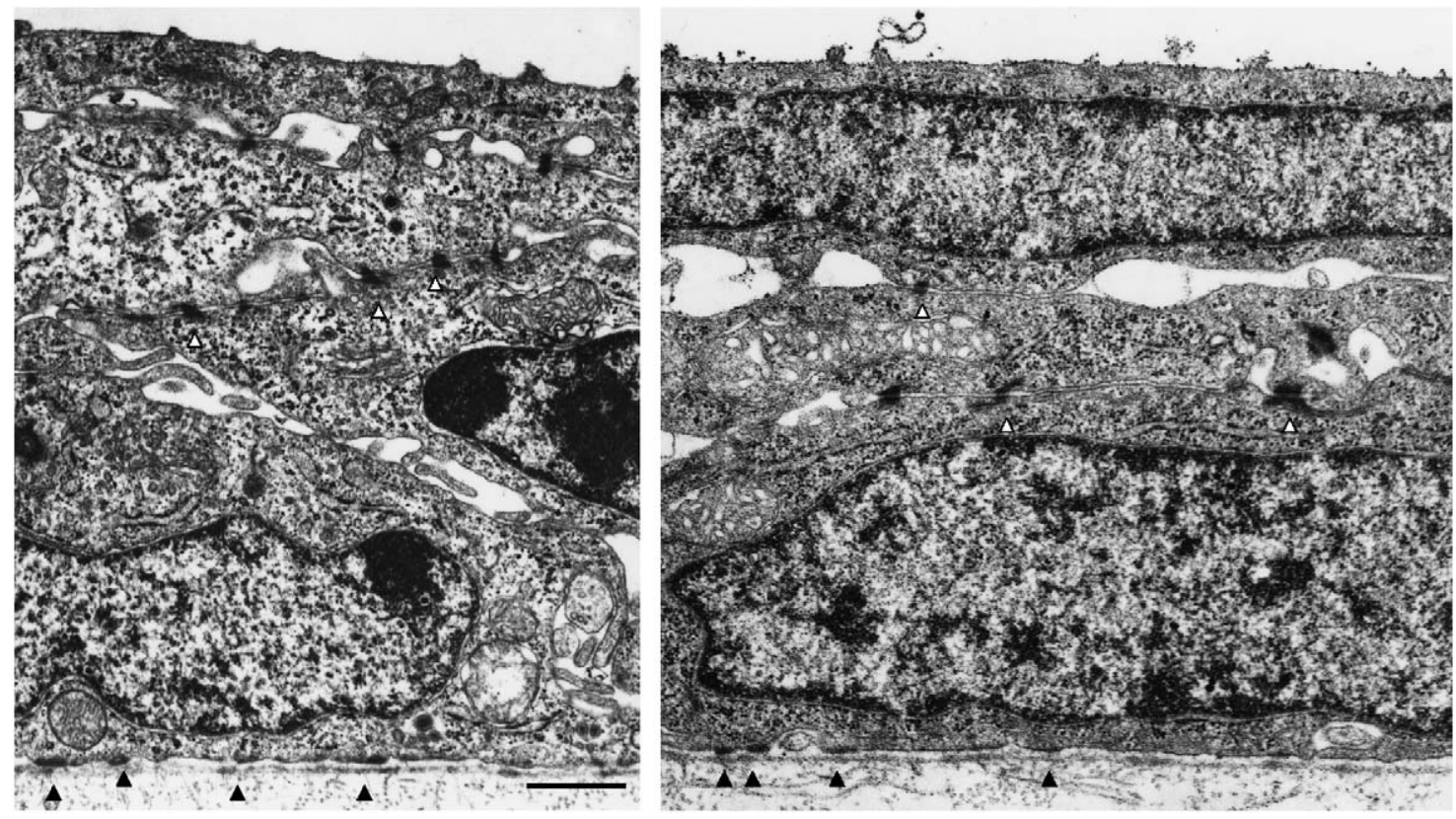

Fig. 1. Electron microscopy of embronic day E18.5 $\mathrm{K}^{-/-}$(left panel) and wild-type (right panel) corneae. Note presence of immature, but normal hemidesmosomes (black triangles) and desmosomes (white triangles) with few keratin filaments attached to the latter. Note the absence of cytolysis. Bar: $0.5 \mu \mathrm{m}$. 

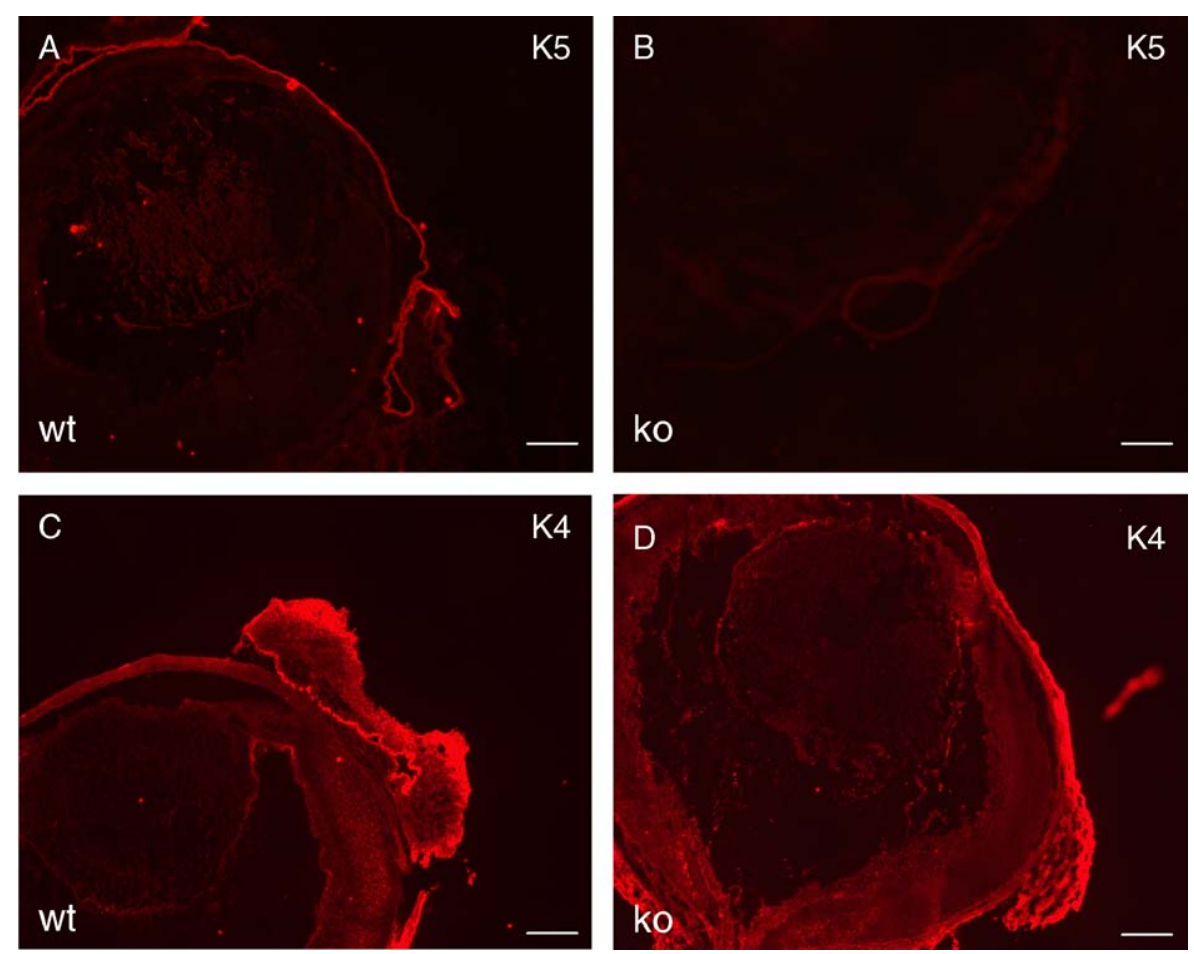

Fig. 2. Immunofluorescence analysis of $\mathrm{K} 5^{-/-}$and wild-type corneae. Expression of $\mathrm{K} 5$ in basal layer of corneal epithelium (A) and absence in $\mathrm{K} 5^{-/-}$(B). In $\mathrm{K} 5^{-/-}$tissue, $\mathrm{K} 4$ was expressed in all layers of the corneal epithelium and in conjunctiva (D); it remained restricted to conjunctiva in wild-type cornea (C). Bars: $40 \mu \mathrm{m}$.

Table 2. Expression of keratin proteins in neonatal mouse cornea and conjunctiva as identified by immunofluorescence analysis

\begin{tabular}{llllll}
\hline & Wt & & \multicolumn{2}{l}{ K5 $^{-/-}$} \\
\cline { 2 - 3 } \cline { 5 - 6 } & Conjunctiva & Cornea & & Conjunctiva & Cornea \\
\hline K1 & + & - & + & - \\
K4 & + & - & + & + \\
K14 & + & + & + & + \\
K15 & + & + & + & + \\
K5 & + & + & & - & - \\
K6 & + & + & + & + \\
K12 & - & + & & - & + \\
K19 & + & - & + & - \\
Kb20 & - & - & - & - & + \\
K23 & - & & - & - & + \\
\hline
\end{tabular}

${ }^{\mathrm{a}}$ Referring to nomenclature by Hesse et al. (2004).

of corneal epithelium and do not fully develop a fullthickness epithelium until eyelids open after two weeks (Sevel and Isaacs, 1988; Zieske, 2004). Given that K5 ${ }^{-/-}$ mice die immediately after birth, it is impossible to detect the role of $\mathrm{K} 5$ during postnatal differentiation of cornea in the $\mathrm{K}^{-/-}$mice. Anyhow, loss of $\mathrm{K} 5$ alters keratin expression in cornea: $\mathrm{K} 4$, which is just normally expressed in the conjunctiva, is expressed in K5 knockout cornea. It will be interesting in the future to analyze the functionality of the $\mathrm{K} 4 / \mathrm{K} 14$ pair in fully developed corneas in an appropriate mouse model.

\section{Lack of a functional murine/rat keratin K3 gene}

We previously reported that the human keratin $\mathrm{K} 3$ gene situated between the genes for keratin $\mathrm{K} 2 \mathrm{p}$ and $\mathrm{K} 4$ has no functional counterpart in the murine genome (Hesse et al., 2004). This raised the question whether the human $\mathrm{K} 3$ gene is the result of a recent gene duplication followed by sequence drift or documents an older gene, which was specifically lost on the lineage leading to mice. We therefore analyzed the region between the murine genes $\mathrm{K} 2 \mathrm{p}$ and $\mathrm{K} 4$ on chromosome 15 in detail and found that it contains sequences related to exons 1 (nt $102,389,191$ to $102,389,729$ ), 2 (nt 102,388,007 to $102,388,207$ ) and 9 (nt $102,386,484$ to $102,386,773$ ) of the human K3 gene, but lacks related sequences for exons 3-8. The predicted murine sequences reveal novel stop codons indicating that the murine K3 pseudogene is not functional. This analysis was extended to the rat genome where counterparts of a K3 pseudogene could be documented on chromosome 7 for exons 1 (nt $140,692,247-140,692,747$ ) and 2 (nt 140,691,071$140,691,255)$ with novel stop codons. Unfortunately, the extremely limited amount of neonatal $\mathrm{K} 5^{-/-}$tissue precluded the RT-PCR analysis of the potential 


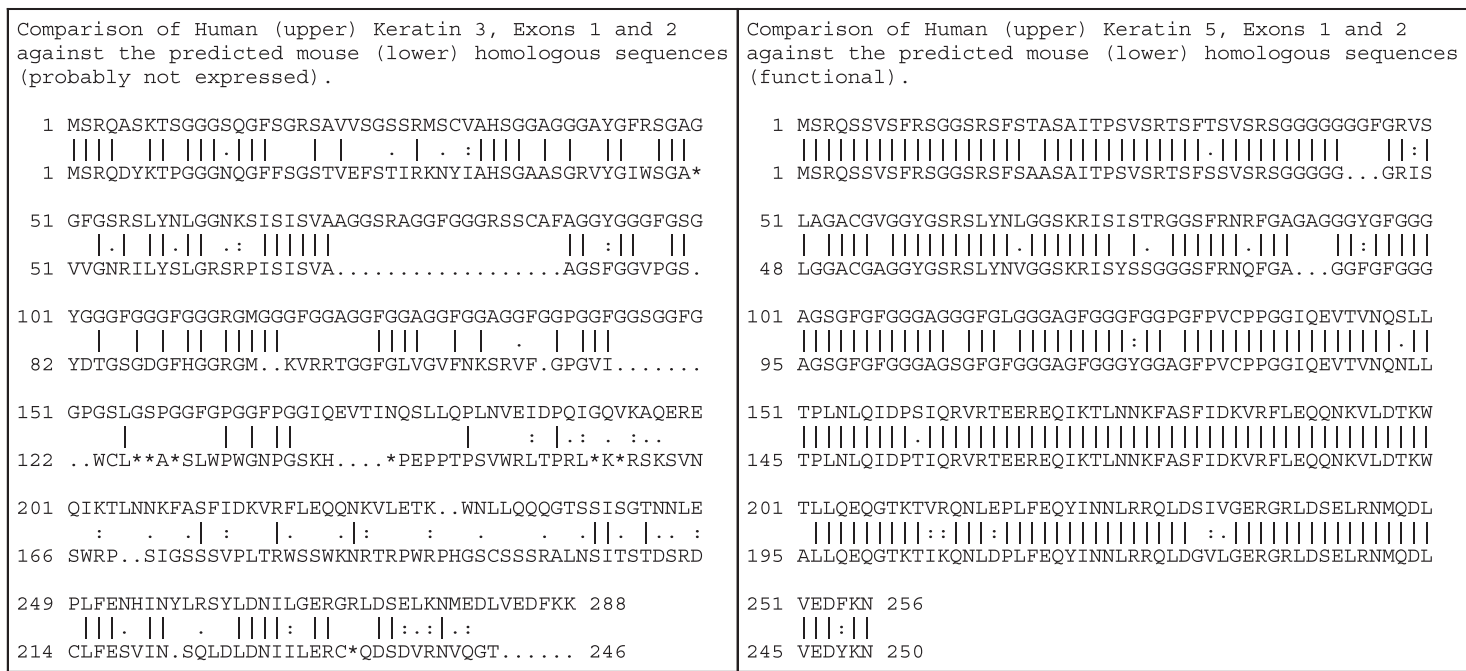

Fig. 3. Comparison of human (upper) and predicted mouse (lower) K3 amino acid sequences encompassing exons 1 and 2. Left panel: K3, right panel: K5 sequences. Identical amino acids are indicated by vertical bars, conserved hydrophobic amino acid residues are marked by (.) and conserved hydrophilic residues by (:). Note the presence of frequent stop codons (*) in the murine K3 sequence.

transcript encoded by murine exons 1 and 2 . In comparison to exons 1 and 2 of the K5 gene, which display $97 \%$ sequence identity between humans and the mouse at the amino acid level, the corresponding K3 sequences are only $22 \%$ identical. Moreover, numerous stop codons disable an open reading frame (Fig. 3). Owing to the poor promoter consensus sequences of the cryptic murine $\mathrm{K} 3$ pseudogene, it is very unlikely that there is residual transcriptional activity.

The combined evidence indicates that the $\mathrm{K} 3$ gene is older than the rodent lineage where it converted to a strongly diverged unprocessed pseudogene. In agreement with this view are results with the monoclonal antibody AE5, which recognizes the K3 keratin in corneas of man, cow, dog and rabbit, but fails to decorate the cornea of the mouse (Chaloin-Dufau et al., 1993). It also does not react on the cornea of the guinea pig (data not shown).

A K3 gene sequence was already earlier established for the rabbit (Wu et al., 1994). We also found a functional K3 gene in the genome drafts of the chimpanzee (chromosome 10, nt 52,696,046-52,702,049) and the dog (chromosome 27, nt 5,331,542-5,337,318). Finally the gene bank contains a predicted cDNA sequence (XP615095) for K3 from the cow (chromosome 5, nt 20,225,554-20,233,962), supported by a partial mRNA sequence (K03533). Protein sequence identities of these K3 keratins range from $97 \%$ (human versus chimpanzee) to $84 \%$ (human versus cow) and $79 \%$ (human versus dog and rabbit). The combined results establish a functional K3 keratin gene in various groups of mammals except the rodents. Normal K3 genes are found in primates (man, chimpanzee), carnivora (dog), artiodactyla (cow) and lagomorpha (rabbit). This gene is converted to an unprocessed pseudogene with very strong sequence drift in rodents (mouse and rat). This finding fits modern mammalian phylogeny where the lagomorpha are a sister group of the rodents (Lindblad-Toh, 2004; Murphy et al., 2001).

Previously, the transcription factors Sp1 and AP-2 were suggested to participate in the differential regulation of K3 and K14 in rabbit corneal cells. These studies have shown binding of both factors to keratin promoter fragments, in agreement with analogous studies by other labs (Wu et al., 1994). While the idea that differential binding of Sp1 and AP-2 are involved in the specific regulation of corneal keratins is attractive, it is not supported by mouse knockout studies. Talbot et al. (1999) have reported an unaltered epidermal keratin expression in AP- $2 \alpha$-deficient mice. Given that there are 5 AP-2 family members, the regulated binding of which to their sites is not well understood, the examination of individual knockout mice does not support their major role in keratin regulation with the possible exception of AP- $2 \gamma$ in the onset of K14 expression in embryonic skin development (Koster et al., 2006).

The existence of keratin expression pairs has been widely considered as an indicator of tissue-specific keratin function, including the postulated role of K6 and K16 in wound healing and alternative keratinocyte differentiation (Wong and Coulombe, 2003). There is increasing evidence, however, that certain keratins can replace each other in vivo, at least in the absence of additional stress. This includes $\mathrm{K} 19$ in $\mathrm{K} 18^{-/-}$mice, $\mathrm{K} 8$ in embryonic epidermis of $\mathrm{K}^{-/-}$mice and now, $\mathrm{K} 4$ in the cornea of $\mathrm{K}^{-/-}$mice (Lu et al., 2005; Magin et al., 
1998), for in vitro data, see (Hatzfeld and Franke, 1985; Yamada et al., 2002). Remarkably, the transcriptional regulation of keratin expression has evolved to support plasticity of keratins. While the K14 gene is under the transcriptional control of $\mathrm{p} 63$ and AP- $2 \gamma$, this is not the case for its partner K5 (Koster et al., 2006). Collectively, there is a need for more sophisticated experiments which need to address whether individual keratins have distinct functions.

\section{References}

Chaloin-Dufau, C., Pavitt, I., Delorme, P., Dhouailly, D., 1993. Identification of keratins 3 and 12 in corneal epithelium of vertebrates. Epithelial Cell Biol. 2, 120-125.

Chiaromonte, F., Yap, V.B., Miller, W., 2002. Scoring pairwise genomic sequence alignments. Pac. Symp. Biocomput. 115-126.

Coulombe, P.A., Hutton, M.E., Letai, A., Hebert, A., Paller, A.S., Fuchs, E., 1991. Point mutations in human keratin 14 genes of epidermolysis bullosa simplex patients: genetic and functional analyses. Cell 66, 1301-1311.

Galvin, S., Loomis, C., Manabe, M., Dhouailly, D., Sun, T.T., 1989. The major pathways of keratinocyte differentiation as defined by keratin expression: an overview. Adv. Dermatol. 4, 277-299 (Discussion 300).

Hatzfeld, M., Franke, W.W., 1985. Pair formation and promiscuity of cytokeratins: formation in vitro of heterotypic complexes and intermediate-sized filaments by homologous and heterologous recombinations of purified polypeptides. J. Cell Biol. 101, 1826-1841.

Herzog, F., Winter, H., Schweizer, J., 1994. The large type II $70-\mathrm{kDa}$ keratin of mouse epidermis is the ortholog of human keratin K2e. J. Invest. Dermatol. 102, 165-170.

Hesse, M., Zimek, A., Weber, K., Magin, T.M., 2004. Comprehensive analysis of keratin gene clusters in humans and rodents. Eur. J. Cell Biol. 83, 19-26.

Karolchik, D., Baertsch, R., Diekhans, M., Furey, T.S., Hinrichs, A., Lu, Y.T., Roskin, K.M., Schwartz, M., Sugnet, C.W., Thomas, D.J., Weber, R.J., Haussler, D., Kent, W.J., 2003. The UCSC genome browser database. Nucleic Acids Res. 31, 51-54.

Koster, M.I., Kim, S., Huang, J., Williams, T., Roop, D.R., 2006. TAp63alpha induces AP-2gamma as an early event in epidermal morphogenesis. Dev. Biol. 289, 253-261.

Kurpakus, M.A., Maniaci, M.T., Esco, M., 1994. Expression of keratins K12, K4 and K14 during development of ocular surface epithelium. Curr. Eye Res. 13, 805-814.

Lane, E.B., Rugg, E.L., Navsaria, H., Leigh, I.M., Heagerty, A.H., Ishida-Yamamoto, A., Eady, R.A., 1992. A mutation in the conserved helix termination peptide of keratin 5 in hereditary skin blistering. Nature 356, 244-246.

Lindblad-Toh, K., 2004. Genome sequencing: three's company. Nature 428, 475-476.

Liu, C.Y., Zhu, G., Westerhausen-Larson, A., Converse, R., Kao, C.W., Sun, T.T., Kao, W.W., 1993. Cornea-specific expression of K12 keratin during mouse development. Curr. Eye Res. 12, 963-974.
Liu, C.Y., Zhu, G., Converse, R., Kao, C.W., Nakamura, H., Tseng, S.C., Mui, M.M., Seyer, J., Justice, M.J., Stech, M.E., Hansen, G.M., Kao, W.W., 1994. Characterization and chromosomal localization of the cornea-specific murine keratin gene Krt1.12. J. Biol. Chem. 269, 24627-24636.

Lloyd, C., Yu, Q.C., Cheng, J., Turksen, K., Degenstein, L., Hutton, E., Fuchs, E., 1995. The basal keratin network of stratified squamous epithelia: defining K15 function in the absence of K14. J. Cell Biol. 129, 1329-1344.

Lu, L., Reinach, P.S., Kao, W.W., 2001. Corneal epithelial wound healing. Exp. Biol. Med. (Maywood) 226, 653-664.

Lu, H., Hesse, M., Peters, B., Magin, T.M., 2005. Type II keratins precede type I keratins during early embryonic development. Eur. J. Cell Biol. 84, 709-718.

Magin, T.M., Schroder, R., Leitgeb, S., Wanninger, F., Zatloukal, K., Grund, C., Melton, D.W., 1998. Lessons from keratin 18 knockout mice: formation of novel keratin filaments, secondary loss of keratin 7 and accumulation of liver-specific keratin 8-positive aggregates. J. Cell Biol. 140, 1441-1451.

Magin, T.M., Reichelt, J., Hatzfeld, M., 2004. Emerging functions: diseases and animal models reshape our view of the cytoskeleton. Exp. Cell Res. 301, 91-102.

Murphy, W.J., Stanyon, R., O’Brien, S.J., 2001. Evolution of mammalian genome organization inferred from comparative gene mapping. Genome Biol. 2, REVIEWS0005.

O’Guin, W.M., Galvin, S., Schermer, A., Sun, T.T., 1987. Patterns of keratin expression define distinct pathways of epithelial development and differentiation. Curr. Top. Dev. Biol. 22, 97-125.

Paladini, R.D., Coulombe, P.A., 1999. The functional diversity of epidermal keratins revealed by the partial rescue of the keratin 14 null phenotype by keratin 16. J. Cell Biol. 146, 1185-1201.

Perng, M.D., Sandilands, A., Kuszak, J., Dahm, R., Wegener, A., Prescott, A.R., Quinlan, R.A., 2004. The intermediate filament systems in the eye lens. Methods Cell Biol. 78, 597-624.

Peters, B., Kirfel, J., Bussow, H., Vidal, M., Magin, T.M., 2001. Complete cytolysis and neonatal lethality in keratin 5 knockout mice reveal its fundamental role in skin integrity and in epidermolysis bullosa simplex. Mol. Biol. Cell 12, 1775-1789.

Quinlan, R.A., Schiller, D.L., Hatzfeld, M., Achtstatter, T., Moll, R., Jorcano, J.L., Magin, T.M., Franke, W.W., 1985. Patterns of expression and organization of cytokeratin intermediate filaments. Ann. NY Acad. Sci. 455, 282-306.

Reichelt, J., Bussow, H., Grund, C., Magin, T.M., 2001. Formation of a normal epidermis supported by increased stability of keratins 5 and 14 in keratin 10 null mice. Mol. Biol. Cell 12, 1557-1568.

Schermer, A., Galvin, S., Sun, T.T., 1986. Differentiationrelated expression of a major $64 \mathrm{~K}$ corneal keratin in vivo and in culture suggests limbal location of corneal epithelial stem cells. J. Cell Biol. 103, 49-62.

Schwartz, S., Kent, W.J., Smit, A., Zhang, Z., Baertsch, R., Hardison, R.C., Haussler, D., Miller, W., 2003. Humanmouse alignments with BLASTZ. Genome Res. 13, 103-107. 
Sevel, D., Isaacs, R., 1988. A re-evaluation of corneal development. Trans. Am. Ophthalmol. Soc. 86, 178-207.

Sun, T.T., Eichner, R., Nelson, W.G., Tseng, S.C., Weiss, R.A., Jarvinen, M., Woodcock-Mitchell, J., 1983. Keratin classes: molecular markers for different types of epithelial differentiation. J. Invest. Dermatol. 81, $109 \mathrm{~s}-115 \mathrm{~s}$.

Swensson, O., Langbein, L., McMillan, J.R., Stevens, H.P., Leigh, I.M., McLean, W.H., Lane, E.B., Eady, R.A., 1998. Specialized keratin expression pattern in human ridged skin as an adaptation to high physical stress. Br. J. Dermatol. 139, 767-775.

Talbot, D., Loring, J., Schorle, H., 1999. Spatiotemporal expression pattern of keratins in skin of AP-2alphadeficient mice. J. Invest. Dermatol. 113, 816-820.

Tong, X., Coulombe, P.A., 2004. A novel mouse type I intermediate filament gene, keratin $17 \mathrm{n}(\mathrm{K} 17 \mathrm{n})$, exhibits preferred expression in nail tissue. J. Invest. Dermatol. 122, 965-970.

Vassar, R., Coulombe, P.A., Degenstein, L., Albers, K., Fuchs, E., 1991. Mutant keratin expression in transgenic mice causes marked abnormalities resembling a human genetic skin disease. Cell 64, 365-380.

Waterston, R.H., Lindblad-Toh, K., Birney, E., Rogers, J., Abril, J.F., Agarwal, P., Agarwala, R., Ainscough, R., Alexandersson, M., An, P., Antonarakis, S.E., Attwood, J., Baertsch, R., Bailey, J., Barlow, K., Beck, S., Berry, E., Birren, B., Bloom, T., Bork, P., Botcherby, M., Bray, N., Brent, M.R., Brown, D.G., Brown, S.D., Bult, C., Burton, J., Butler, J., Campbell, R.D., Carninci, P., Cawley, S., Chiaromonte, F., Chinwalla, A.T., Church, D.M., Clamp, M., Clee, C., Collins, F.S., Cook, L.L., Copley, R.R., Coulson, A., Couronne, O., Cuff, J., Curwen, V., Cutts, T., Daly, M., David, R., Davies, J., Delehaunty, K.D., Deri, J.,
Dermitzakis, E.T., Dewey, C., Dickens, N.J., Diekhans, M., Dodge, S., Dubchak, I., Dunn, D.M., Eddy, S.R., Elnitski, L., Emes, R.D., Eswara, P., Eyras, E., Felsenfeld, A., Fewell, G.A., Flicek, P., Foley, K., Frankel, W.N., Fulton, L.A., Fulton, R.S., Furey, T.S., Gage, D., Gibbs, R.A., Glusman, G., Gnerre, S., Goldman, N., Goodstadt, L., Grafham, D., Graves, T.A., Green, E.D., Gregory, S., Guigo, R., Guyer, M., Hardison, R.C., Haussler, D., Hayashizaki, Y., Hillier, L.W., Hinrichs, A., Hlavina, W., Holzer, T., Hsu, F., Hua, A., Hubbard, T., Hunt, A., Jackson, I., Jaffe, D.B., Johnson, L.S., Jones, M., Jones, T.A., Joy, A., Kamal, M., Karlsson, E.K., et al., 2002. Initial sequencing and comparative analysis of the mouse genome. Nature 420, 520-562.

Wolosin, J.M., Budak, M.T., Akinci, M.A., 2004. Ocular surface epithelial and stem cell development. Int. J. Dev. Biol. 48, 981-991.

Wong, P., Coulombe, P.A., 2003. Loss of keratin 6 (K6) proteins reveals a function for intermediate filaments during wound repair. J. Cell Biol. 163, 327-337.

Wu, R.L., Chen, T.T., Sun, T.T., 1994. Functional importance of an Sp1- and an NF $\kappa$ B-related nuclear protein in a keratinocyte-specific promoter of rabbit K3 keratin gene. J. Biol. Chem. 269, 28450-28459.

Yamada, S., Wirtz, D., Coulombe, P.A., 2002. Pairwise assembly determines the intrinsic potential for self-organization and mechanical properties of keratin filaments. Mol. Biol. Cell 13, 382-391.

Zhang, H., Hara, M., Seki, K., Fukuda, K., Nishida, T., 2005. Eyelid fusion and epithelial differentiation at the ocular surface during mouse embryonic development. Jpn. J. Ophthalmol. 49, 195-204.

Zieske, J.D., 2004. Corneal development associated with eyelid opening. Int. J. Dev. Biol. 48, 903-911. 